\title{
CRESCIMENTO, DESENVOLVIMENTO E PRODUÇÃO DE MORANGUEIRO A PARTIR DE MUDAS COM DIFERENTES VOLUMES DE TORRÃO ${ }^{1}$
}

\author{
CARINE COCCO ${ }^{2}$, MICHÉL ALDRIGHI GONÇALVES ${ }^{3}$, LUCIANO PICOLOTTO ${ }^{4}$, \\ LETÍCIA VANNI FERREIRA ${ }^{5}$, LUIS EDUARDO CORRÊA ANTUNES ${ }^{6}$
}

RESUMO - O objetivo deste estudo foi avaliar a influência do volume de alvéolos em bandejas no crescimento, no desenvolvimento de mudas e na produção de frutas do morangueiro. Os tratamentos consistiram em quatro volumes de alvéolos (50; 100; 180 e 312 mL) e duas cultivares ('Camarosa' e 'Aromas'), em delineamento experimental de blocos ao acaso, com quatro repetições, nove plantas por parcela, conduzido no período entre abril e dezembro de 2011. Avaliaram-se os seguintes parâmetros: qualidade, crescimento, desenvolvimento das mudas e produção de frutas. Mudas com torrão produzidas em recipientes com maior volume de alvéolos proporcionaram maior precocidade e produção, em decorrência do maior diâmetro da coroa e a massa seca de parte aérea e raízes. Obteve-se correlação significativa entre a massa seca de raízes, massa seca da parte aérea e o diâmetro da coroa com a produção precoce de frutas. A qualidade da muda influencia diretamente na precocidade e na produção de frutas de morangueiro.

Termos para indexação: Fragaria $x$ ananassa, propagação, mudas nacionais, qualidade, precocidade.

\section{GROWTH, DEVELOPMENT AND YIELD OF STRAWBERRY FROM SEEDLINGS WITH DIFFERENT CLOD VOLUMES}

\begin{abstract}
The aim of this study was to evaluate the influence of alveoli volume in trays on seedling growth and development, and fruit production of strawberry plants. The treatments consisted of four alveoli volumes (50, 100, 180 and $312 \mathrm{ml}$ ) and two cultivars ('Camarosa' and 'Aromas') in experimental design of randomized blocks with four replications, nine plants per plot, being conducted between April and December 2011. Were evaluated the ensuing parameters: quality, seedling growth and development and fruit yield. Seedlings in clods produced in containers with larger alveoli volume provided greater earliness and yield, due to increase in crown diameter, and dry mass of shoots and roots. We obtained a significant correlation between roots dry mass, shoot dry mass and crown diameter with the early fruit yield. The seedlings quality directly influence on the earliness and fruit yield of strawberry.

Index terms: Fragaria $x$ ananassa, propagation, national transplants, quality, earliness.
\end{abstract}

\footnotetext{
${ }^{1}$ (Trabalho 250-14). Recebido em: 03-09-2014. Aceito para publicação em: 26-05-2015. Parte da tese de doutorado da primeira autora. ${ }^{2}$ Eng.Agr.Dra.Professora na Universidade de Caxias do Sul, Caxias do Sul - RS. E-mail: ccocco@ucs.br

${ }^{3}$ Eng. Agr. Dr., Bolsista Pós-doc CAPES/Embrapa, Embrapa Clima Temperado, Pelotas - RS, Brasil. E-mail: aldrighimichel@gmail.com ${ }^{4}$ Eng. Agr. Dr. Professor da Universidade Federal de Santa Catarina, Curitibanos - SC. E-mail: picolotto.1@ufsc.br

${ }^{5}$ Eng. Agr. MsC. Doutoranda do Programa de Pós-Graduação em Agronomia, Universidade Federal de Pelotas, Pelotas - RS. E-mail: letivf@hotmail.com

${ }^{6}$ Eng. Agr. Dr. Pesquisador Embrapa Clima Temperado, Pelotas - RS. Bolsista CNPq. E-mail: luis.antunes@embrapa.br
} 


\section{INTRODUÇÃO}

O plantio na época adequada é uma das etapas mais importantes para que o morangueiro possa expressar seu potencial produtivo (RAHMAN et al., 2014). Em regiões de clima ameno, como Pelotas-RS, a época de plantio recomendada é entre março e abril, visto que, a partir de maio, verificam-se temperaturas favoráveis para a floração e a frutificação, na faixa de $13-26{ }^{\circ} \mathrm{C}$ (PASSOS et al., 2015). Entretanto, no Rio Grande do Sul, devido à baixa disponibilidade e qualidade das mudas nacionais, o plantio é feito nos meses de maio e junho (ANTUNES; PERES, 2013). Nesta época, os produtores obtem as mudas de viveiros chilenos e argentinos. Como consequência, a produção precoce, durante os meses de inverno, é limitada, período em que os preços são mais elevados em razão da baixa oferta da fruta no mercado.

Uma das alternativas propostas para a superação deste entrave é o uso de mudas com torrão, produzidas a partir de plantas-matrizes cultivadas em ambiente protegido durante a primavera e o verão, utilizando sistemas de produção fora do solo, com substrato esterilizado (MENZEL; SMITH et al., 2012). A principal vantagem deste tipo de muda é a possibilidade de escalonar a produção das mesmas, de maneira que o plantio na lavoura comercial possa ser realizado na época recomendada (DURNER et al., 2002). Ademais, o sistema radicular cresce envolvido por substrato, isento de patógenos, minimizando a exposição a doenças provenientes do cultivo no solo (HUANG et al., 2011) e o estresse por ocasião do transplante. Estes elementos contribuem para o melhor desenvolvimento das mudas no campo e precocidade na produção de frutas (COCCO et al., 2010).

Por outro lado, garantir o crescimento adequado da muda em um volume limitado de substrato é uma das dificuldades deste sistema de produção. Mudas com sistema radicular pouco desenvolvido, quando transplantadas para o campo, têm dificuldade de compensar a evapotranspiração, mesmo se bem irrigadas (DURNER et al., 2002). Assim, quanto menor for o espaço disponível às raízes, mais difícil será o suprimento de fatores de produção que assegurem satisfatório crescimento e desenvolvimento da muda (SANTOS et al., 2012).

A tecnologia de produção de mudas em bandejas já é bem conhecida e adaptada para as condições climáticas e sistemas de produção em diversos países, como Estados Unidos, México e Europa (DURNER et al., 2002; DAVALOSGONZALES et al., 2009). No entanto, no Brasil, existem poucos estudos, havendo a necessidade de adequação desta técnica. Com base nisso, o objetivo deste trabalho foi avaliar a influência do volume de alvéolos em bandejas, no crescimento, desenvolvimento de mudas e produção de frutas do morangueiro.

\section{MATERIAL E MÉTODOS}

O experimento foi conduzido na área experimental pertencente à Embrapa Clima Temperado, localizada no município de PelotasRS, cujas coordenadas geográficas são: $31^{\circ} 40^{\prime} \mathrm{S}$ e $52^{\circ} 26^{\prime} \mathrm{W}$; $60 \mathrm{~m}$ de altitude, no período de abril a dezembro de 2011.

As mudas de morangueiro, para o plantio no campo, foram produzidas a partir de plantas matrizes propagadas em estufa agrícola, em sistema semihidropônico, constituído por calhas acondicionadas sobre bancadas de madeira, utilizando como substrato casca de arroz carbonizada. As matrizes, provenientes da cultura de tecidos, adquiridas da empresa Multiplanta ${ }^{\circledR}$, foram plantadas em meados de setembro de 2010 e emitiram estolões durante a primavera e o verão. A irrigação foi feita conforme a necessidade da cultura, sendo utilizadas fitas gotejadoras com distância entre gotejos de 15 $\mathrm{cm}$ e a nutrição feita através de solução nutritiva recomendada por Furlani e Fernandes Júnior (2004).

As mudas comerciais foram produzidas em março, a partir de pontas de estolões emitidas pelas plantas-matrizes e colocados para enraizar em bandejas contendo substrato organomineral Holambra $^{\circledR}$, originando mudas com torrão. Os estolões foram coletados, limpos e preparados no período da manhã. Foram descartadas as pontas de estolão velhas, com os primórdios radiculares suberizados e aquelas muito jovens, que não apresentavam desenvolvimento de primórdios radiculares. Utilizaram-se pontas de estolão com diâmetro da coroa entre 5 e $7 \mathrm{~mm}$ e mantidos apenas os dois trifólios mais jovens.

O enraizamento foi realizado em bandejas de polipropileno preto, com diferentes tamanhos de alvéolos, fabricadas pela empresa Agrototal ${ }^{\circledR}$, de Holambra-SP. Os tratamentos consistiram em bandejas com os seguintes volumes de alvéolos: 50; 100; 180 e 312 mL e duas cultivares de morangueiro: 'Camarosa' (dias curtos) e 'Aromas' (dias neutros), conduzidas em delineamento experimental de blocos ao acaso, com quatro repetições e nove plantas em cada unidade experimental. As bandejas foram preenchidas com substrato comercial (HS Hortaliças $^{\circledR}$ ), produzido pela empresa Holambra Substratos ${ }^{\circledR}$. Após o plantio nas bandejas, as mudas 
permaneceram sob nebulização intermitente, com frequência de irrigação de 10 segundos a cada 5 minutos, durante os primeiros dez dias. Após este período, realizou-se a aclimatização das mudas, transferindo-as para as bancadas de crescimento, onde foram mantidas durante 45 dias, sendo irrigadas por microaspersão e fertirrigadas três vezes por semana, com solução nutritiva recomendada por Furlani e Fernandes Júnior (2003), diluída para 50\% da concentração inicial. Antes do plantio, as mudas passaram por um período de vernalização em câmara fria, durante dez dias, a temperatura de $4,0^{\circ} \mathrm{C} \pm 0,1^{\circ} \mathrm{C}$, com luz artificial através de lâmpadas fluorescentes e, posteriormente, aclimatizadas em condições naturais de radiação solar e temperatura, durante quatro dias.

Por ocasião do plantio, realizou-se o preparo do solo através de aração, gradagem e encanteiramento. Juntamente com o preparo do solo, efetuou-se a correção da fertilidade do solo de acordo com os resultados da análise, baseado nas recomendações para a cultura do morangueiro descritas no Manual de Adubação e Calagem para os Estados do Rio Grande do Sul e Santa Catarina (SOCIEDADE BRASILEIRA DE CIÊNCIA DO SOLO/RS,2004). O plantio das mudas no campo foi realizado em 19 de abril de 2011, no sistema de produção convencional, com três fileiras de plantas em cada canteiro, em espaçamento de $0,30 \mathrm{~m}$ entre plantas e entrelinhas. A irrigação foi por gotejamento, com duas linhas de fitas gotejadoras em cada canteiro e espaçamento entre orifícios de $0,15 \mathrm{~m}$. Sobre os canteiros, colocou-se mulching de cor preta, com $40 \mu \mathrm{m}$ de espessura e, posteriormente, foram construídos túneis baixos, com filme de polietileno de baixa densidade (PEDB), transparente, com 100 $\mu \mathrm{m}$ de espessura. O manejo dos túneis, as irrigações e fertirrigações durante todo o ciclo da cultura foram feitos por sistema de gotejo e baseadas nas recomendações de Santos e Medeiros (2003).

No momento do plantio a campo, amostras constituídas de 20 mudas por tratamento foram selecionadas para realizar as seguintes avaliações: diâmetro de coroa $(\mathrm{mm})$, com o auxílio de um paquímetro digital, número de folhas, através de contagem, massa seca de parte aérea (g) e massa seca de raízes $(\mathrm{g})$, obtidas após secagem em estufa de circulação forçada de ar, na temperatura de $65^{\circ} \mathrm{C}$, até obter massa constante entre duas determinações consecutivas. Avaliou-se ainda a sobrevivência das mudas, semanalmente, durante as primeiras três semanas. Contabilizou-se o número de folhas por planta no pleno florescimento, quando $50 \%$ das plantas continham ao menos uma flor, e a data de inicio da produção, considerada quando foi colhida a primeira fruta na parcela.

A colheita iniciou-se no mês de junho, estendendo-se até 27 de dezembro do mesmo ano. As frutas foram colhidas quando apresentavam $100 \%$ da epiderme com coloração avermelhada, no estádio de maturação completa, sendo contadas e pesadas em balança digital. O somatório do número e da massa de frutas obtidas em todas as colheitas, ao longo do experimento, foi dividido pelo número de plantas na parcela experimental, para obter-se a produção $\left(\mathrm{g}_{\text {planta }}{ }^{-1}\right)$. O tamanho médio de fruta $\left(\mathrm{g} \mathrm{fruta}^{-1}\right)$ foi obtido pelo quociente entre a massa fresca por planta e o número de frutas por planta. Para as avaliações, foram contabilizadas apenas as frutas comerciais, com massa fresca superior a três gramas (CEAGESP, 2002). Foi considerada produção precoce aquela obtida desde a primeira colheita até o final do mês de setembro.

Os dados foram submetidos à análise de variância, e as médias dos tratamentos foram comparadas entre si, pelo teste de Tukey, a 5\% de probabilidade de erro, através do Programa estatístico Sisvar (FERREIRA, 2011). As correlações entre os parâmetros avaliados foram analisadas através do coeficiente de correlação de Pearson $(\mathrm{p}<0,05)$.

\section{RESULTADOS E DISCUSSÃO}

Obteve-se interação significativa entre as cultivares e os volumes de substrato, para os parâmetros diâmetro da coroa, número de folhas e massa seca de parte aérea, avaliados no momento do plantio (Tabela 1). Para 'Aromas', o uso de bandejas contendo alvéolos com maior volume $(312 \mathrm{~mL})$ resultou em mudas com maior diâmetro de coroa (DC), número de folhas (NF) e massa seca de parte aérea (MSPA). Para 'Camarosa', os resultados foram semelhantes, com exceção do número de folhas, que não apresentou diferença entre os volumes testados. A comparação entre as cultivares dentro de cada volume de alvéolo revelou comportamento semelhante entre ambas, para a maioria dos parâmetros avaliados, nos volumes de 180 e $312 \mathrm{~mL}$. Entretanto, em alvéolos menores (50 e $100 \mathrm{~mL}$ ), 'Camarosa' apresentou maior diâmetro de coroa e menor massa seca da parte aérea em relação à 'Aromas'.

O início da produção foi verificado em meados de junho de 2011, cerca de 50 a 60 dias após o transplante (Tabela 2), correspondendo ao final do outono, período em que há baixa oferta da fruta no mercado e, consequentemente, preços mais elevados, constituindo-se, assim, uma excelente alternativa para os produtores que almejam maiores rendimentos 
econômicos com a cultura. O efeito das cultivares não foi significativo para a precocidade. Entretanto, este parâmetro apresentou resposta significativa em relação ao volume do alvéolo na bandeja. Assim, mudas provenientes de bandejas com alvéolos de $312 \mathrm{~mL}$ propiciaram precocidade na produção quando comparadas com aquelas provenientes das bandejas com alvéolos de $50 \mathrm{~mL}$. Cocco et al. (2010) esclarecem que o estado fisiológico da muda e as condições nas quais são produzidas afetam a indução floral e, consequentemente, a precocidade de produção das cultivares de morangueiro. Assim, mudas vigorosas, como aquelas produzidas nos alvéolos de $312 \mathrm{~mL}$, apresentam maior sensibilidade ao fotoperíodo e temperatura, estimulando a indução floral antecipadamente (KUROKURA et al., 2013).

A massa seca de raízes e o número de folhas no pleno florescimento não foram influenciados pela interação entre os fatores estudados, apresentando somente efeito isolado para cada um deles (Tabela 2). Mudas com maior massa seca de raízes foram obtidas utilizando-se de bandejas com alvéolos de $312 \mathrm{~mL}$, diferindo dos demais volumes, provavelmente, devido à maior disponibilidade de fatores de crescimento, como nutrientes, água e maior aeração e promovendo maior massa seca da parte aérea (Tabela 1). De maneira geral, observou-se que bandejas com alvéolos de maior volume de substrato propiciaram melhor desenvolvimento da muda. As mudas produzidas em bandejas de 50 e 100 $\mathrm{mL}$ apresentaram os menores valores de massa seca de raízes, não diferindo entre si. A principal explicação é a uma limitação no crescimento do sistema radicular, causada pelo espaço reduzido. Neste sentido, apesar do maior gasto com substrato, em função do maior volume de alvéolos, a adequada formação da muda deve ser considerada, visando ao sucesso após o transplante, que pode resultar em maior produtividade, com precocidade na produção. Estes resultados são de grande importância, conforme mencionado por Huang et al. (2011), que relatam que quanto maior a massa radicular, maior a quantidade de reservas disponíveis para o crescimento no intervalo entre o transplante e a formação de novas raízes. Além disso, segundo Torres-Quezada et al. (2015), o efetivo enraizamento, seguido da retomada do crescimento da planta após o processo de transplante são favorecidos por tecidos com elevado acúmulo de matéria seca.

No pleno florescimento a campo, a contagem do número de folhas confirmou os resultados obtidos no momento do plantio para este mesmo parâmetro. As mudas produzidas em bandejas com alvéolos de maior volume produziram maior número de folhas, diferindo das demais. Por outro lado, aquelas produzidas em bandejas com volumes menores, embora tenham incrementado esta variável após o plantio, mantiveram sua condição inferior de qualidade. Em relação às cultivares, 'Camarosa' apresentou maior produção de folhas, com média de 8,2 folhas por planta, diferindo de 'Aromas', que apresentou 6,1 folhas, além de apresentar maior massa seca do sistema radicular. Segundo Bartczak et al. (2010), a produção de frutas no morangueiro depende da produção fotossintética, a qual está estreitamente relacionada ao tamanho do aparato de assimilação da planta. Assim, plantas com maior número de folhas possuem capacidade fotossintética mais elevada, resultando em melhor suprimento de carboidratos durante a frutificação.

Os parâmetros produtivos avaliados não foram influenciados pela interação entre as cultivares e o volume de alvéolos nas bandejas (Tabela 3). No período precoce, a cultivar 'Camarosa' produziu maior número de frutas produzidas $(23,8$ frutas planta $\left.^{-1}\right)$, diferindo de 'Aromas', que produziu, em média, 21,0 frutas. No entanto, a massa fresca de frutas foi similar entre as duas cultivares, sendo 419,6 g planta ${ }^{-1}$ para 'Aromas' e 462,2 g planta $^{-1}$ para 'Camarosa'. Considerando-se o ciclo total de produção de frutas, que foi de junho a dezembro, a produção, em número e massa fresca de frutas, não diferiu significativamente entre as cultivares avaliadas, com média de 58,7 frutas planta $^{-1}$ e 912,9 $\mathrm{g} \mathrm{planta}^{-1}$, respectivamente. Apesar de se tratar de cultivares com respostas diferenciadas ao fotoperíodo e com características morfológicas distintas, a semelhança na produção de frutas entre as duas cultivares não é surpreendente, uma vez que resultados semelhantes foram também verificados em estudos conduzidos por Oliveira e Scivittaro (2006) e Calvete et al. (2010).

O volume de alvéolos influenciou na produção precoce de frutas, tanto em número quanto em massa fresca (Tabela 3). As mudas crescidas em bandejas contendo alvéolos de maior volume $(312 \mathrm{~mL})$ apresentaram maiores valores para estes parâmetros no período precoce de produção, diferindo dos demais volumes avaliados. A massa fresca de frutas neste período foi $33,9 \%$ superior em mudas crescidas em bandejas com alvéolos de $312 \mathrm{~mL}$, em relação àquelas crescidas em alvéolos de $50 \mathrm{~mL}$, não havendo diferença significativa para este parâmetro entre as mudas produzidas em bandejas contendo 50; $100 \mathrm{ou}$ $180 \mathrm{~mL}$ de substrato.

Considerando-se o período total de produção, não houve efeito dos volumes de alvéolos sobre o número de frutas produzidas; no entanto, observou- 
se influência sobre a massa fresca de frutas. Mudas produzidas em bandejas com alvéolos de $312 \mathrm{~mL}$ produziram 1.034,5 $\mathrm{g}_{\text {planta }}{ }^{-1}$ de morangos, não diferindo daquelas produzidas em alvéolos de 50 e $180 \mathrm{~mL}\left(911,0\right.$ e $\left.883,8 \mathrm{~g} \mathrm{planta}^{-1}\right)$. O tamanho médio de frutas, tanto no período precoce, como naquele obtido no ciclo total de produção, não foi influenciado pelas cultivares, tampouco pelo volume de substrato no alvéolo durante o crescimento da muda. A elevada produção de frutas obtida neste estudo, especialmente aquela referente ao período precoce, confirma o potencial deste tipo de muda como alternativa para o plantio na época indicada (PASSOS et al., 2015), em conjunto com adequadas práticas de cultivo e manejo das plantas no campo (RAHMAN et al., 2014). Desta forma, em regiões como o Sul do Brasil, é possível antecipar o início da produção de frutas e obter melhores preços devido à baixa oferta nos meses de maio a agosto.

A obtenção de mudas de morangueiro vigorosas em recipientes de maior volume de substrato foi verificada, também, por outros autores (BISH et al., 2002; GIMÉNEZ et al., 2009; HUANG et al., 2011). Estes estudos têm relatado que o tamanho da célula ou o volume do recipiente podem causar restrições ao crescimento radicular. Em decorrência, há um impacto negativo no crescimento da parte aérea, podendo inclusive afetar a recuperação da planta ao estresse pós-transplante e seu crescimento posterior no campo (SANTOS et al., 2012).

A principal explicação para estas diferenças pode ser atribuída à restrição no crescimento das mudas decorrente da limitação do volume a ser explorado pelo sistema radicular. Volumes maiores de substrato possibilitam maior crescimento de raízes. Como consequência, há um elevado aporte hídrico e nutricional disponível, que promove maior produção de massa vegetativa, gerando maior acúmulo de substâncias de reserva na coroa através da fotossíntese (SANTOS et al., 2012). Esta hipótese é sustentada pelos resultados obtidos neste trabalho com mudas produzidas em bandejas contendo maior volume de alvéolos. Como resultado disso, é possível obter mudas mais vigorosas no momento do transplante no campo, influenciando positivamente seu desempenho durante o período inicial da frutificação, quando parte da produção é dependente das reservas acumuladas durante o crescimento da muda (MENZEL; SMITH et al., 2012; TORRESQUEZADA et al., 2015).

A produção de mudas em alvéolos com volumes reduzidos, apesar de mais econômica do ponto de vista do uso de substrato e espaço físico no ambiente de crescimento, pode ser prejudicial à produção pois, em alvéolos com pequeno volume, o espaço físico e a quantidade de substrato podem ser insuficientes para o crescimento adequado do sistema radicular, podendo limitar a expressão do potencial genético das cultivares (GIMÉNEZ et al., 2009). A provável causa é devido à maior concentração de raízes em alvéolos menores, com maior demanda de oxigênio e de renovação de $\mathrm{CO}_{2}$. Além disso, a produção de mudas em alvéolos menores requer irrigações mais frequentes para suprimento da demanda de água, pois a quantidade de substrato pode não ser suficiente para a retenção da quantidade de água necessária para manter a taxa de crescimento da muda (HUANG et al., 2011). No entanto, irrigações muito frequentes podem ocasionar a lixiviação de nutrientes, sendo necessária uma complementação mineral. Por outro lado, pode-se levantar como desvantagem do uso de bandejas com alvéolos de maior volume, o maior gasto com substrato, aliado à menor produção de mudas por área em ambiente protegido.

As mudas obtidas em alvéolos com menor volume $(50 \mathrm{~mL})$, de maneira geral, apresentaram menor crescimento em diâmetro da coroa e massa seca, em comparação com aquelas de $312 \mathrm{~mL}$, e este tipo de resposta foi semelhante para o número de frutas e massa fresca no período precoce de produção. A correlação de Pearson revelou-se significativa entre os parâmetros biométricos considerados (diâmetro da coroa, massa seca da parte aérea e massa seca de raiz) e a produção de frutas no período precoce (Figura 1A, 1B, 1C). A relação linear entre as variáveis demonstra que um incremento nos parâmetros vegetativos da muda corresponde a um aumento na produção precoce de frutas $\left(\mathrm{g} \mathrm{planta}^{-1}\right)$. Corroborando estes resultados, Bartczak et al. (2010), em estudo realizado na Polônia, verificaram correlação positiva entre parâmetros de qualidade da muda, como a massa seca de parte aérea, o número de o coroas, número e o comprimento de raízes com a produção de frutas a partir de mudas com torrão.

Obteve-se correlação significativa entre a massa seca de raízes com os demais parâmetros de qualidade da muda. Quanto maior o diâmetro da coroa (Figura 1D), massa seca de parte aérea (Figura 1E) e número de folhas (Figura 1F), maior a produção precoce de frutas. Por sua vez, a massa seca de raízes está diretamente associada com o diâmetro da coroa, a massa seca de parte aérea e o número de folhas, confirmando a importância das raízes e coroa na qualidade da muda com torrão. A produção precoce de frutas no morangueiro está diretamente correlacionada à qualidade da muda no momento do plantio. Mudas malformadas podem 
debilitar e comprometer todo o desenvolvimento da cultura, aumentando seu ciclo e levando a perdas na produção. Neste sentido, Menzel e Smith (2012) citam que os parâmetros de qualidade em mudas com torrão, que possuem maior influência na produção do morangueiro, são o diâmetro da coroa, o volume e a qualidade do sistema radicular e a massa da parte aérea

Notou-se, durante o transplante no campo, que o sistema radicular das mudas produzidas em alvéolos com maior volume não envolvia completamente o torrão de substrato, acarretando, em alguns casos, o rompimento de parte do torrão, dificultando a operação de plantio. Com base nisso, é possível inferir que o período de 55 dias, no qual as mudas permaneceram nas bandejas, não foi suficiente para que o sistema radicular explorasse todo o volume de substrato disponível em bandejas de $312 \mathrm{~mL}$. Bish et al. (2002) explicam que as mudas precisam de aproximadamente 10 semanas para extrair o máximo benefício em alvéolos com 150 a $300 \mathrm{~mL}$, dependendo das condições climáticas durante o período de crescimento no verão. No norte da Europa, as mudas permanecem em torno de quatro meses nestes recipientes maiores, sendo plantadas com botões florais já emitidos, para a produção precoce de frutas (DURNER et al., 2002).

O uso de bandejas com volumes de alvéolos maiores possibilita a obtenção de mudas com elevada qualidade fisiológica e potencial produtivo. Estudos adicionais devem ser conduzidos com foco na definição da melhor data de plantio para este tipo de muda, em cada região produtora. Além disso, fazse necessário avaliar a interação entre o tempo de crescimento da muda na bandeja com o volume dos alvéolos e seu efeito sobre o crescimento da coroa e do sistema radicular e a produção precoce no campo. Por fim, mudas com torrão de morangueiro podem ser utilizadas com sucesso para a produção precoce de frutas em regiões de clima mais frio, como o Rio Grande do Sul, reduzindo, assim, a dependência de mudas importadas e aumentando a rentabilidade para os produtores.

TABELA 1 - Diâmetro da coroa (DC), número de folhas (NF) e massa seca de parte aérea (MSPA) em mudas de morangueiro das cultivares Aromas e Camarosa, produzidas em diferentes volumes de alvéolo da bandeja. Pelotas, 2015.

\begin{tabular}{|c|c|c|c|c|c|c|}
\hline \multirow{2}{*}{$\begin{array}{c}\text { Volumes de alvéolo } \\
(\mathrm{mL})\end{array}$} & \multicolumn{2}{|c|}{$\mathrm{DC}(\mathrm{mm})$} & \multicolumn{2}{|r|}{ NF } & \multicolumn{2}{|c|}{ MSPA (g) } \\
\hline & Aromas & Camarosa & Aromas & Camarosa & Aromas & Camarosa \\
\hline 50 & $5,5 \mathrm{cB}^{*}$ & $6,4 \mathrm{bA}$ & $3,5 \mathrm{cA}$ & $3,9 \mathrm{aA}$ & $1,0 \mathrm{bA}$ & $0,4 \mathrm{cB}$ \\
\hline 100 & $5,7 \mathrm{cB}$ & $6,6 \mathrm{bA}$ & $2,9 \mathrm{cB}$ & $4,1 \mathrm{aA}$ & $1,1 \mathrm{bA}$ & $0,3 \mathrm{cB}$ \\
\hline 180 & $6,9 \mathrm{bA}$ & $6,7 \mathrm{bA}$ & $4,6 \mathrm{bA}$ & $4,1 \mathrm{aA}$ & $1,3 \mathrm{bA}$ & $1,1 \mathrm{bA}$ \\
\hline 312 & $8,2 \mathrm{aA}$ & $8,2 \mathrm{aA}$ & $5,8 \mathrm{aA}$ & $4,9 \mathrm{aB}$ & $1,8 \mathrm{aA}$ & $1,8 \mathrm{aA}$ \\
\hline $\mathrm{CV}(\%)$ & & 5,1 & & 12,7 & & 8,3 \\
\hline
\end{tabular}

*Médias seguidas por letras distintas, minúsculas nas colunas e maiúsculas nas linhas, diferem entre si, pelo teste de Tukey, a $5 \%$ de probabilidade de erro.

TABELA 2 - Massa seca de raízes (MSR) em mudas de morangueiro no plantio, número de folhas no pleno florescimento (NFPF) e número de dias, desde o plantio até à primeira colheita (NDIP), em plantas de morangueiro provenientes de mudas produzidas em diferentes volumes de alvéolos na bandeja. Pelotas, 2015.

\begin{tabular}{lccc}
\hline Cultivares & MSR & NFPF & NDIP \\
\hline Aromas & $\left(\right.$ g planta $\left.^{-1}\right)$ & dias \\
Camarosa & $0,7 \mathrm{~b}^{*}$ & $6,1 \mathrm{~b}$ & $57,7^{\mathrm{ns}}$ \\
\hline Volumes de substrato $(\mathrm{mL})$ & $0,8 \mathrm{a}$ & $8,2 \mathrm{a}$ & 59,8 \\
\hline 50 & & $5,0 \mathrm{~b}$ & $64 \mathrm{a}$ \\
100 & $0,5 \mathrm{c}$ & $5,4 \mathrm{~b}$ & $59 \mathrm{ab}$ \\
180 & $0,6 \mathrm{c}$ & $6,1 \mathrm{ab}$ & $59 \mathrm{ab}$ \\
312 & $0,8 \mathrm{~b}$ & $8,1 \mathrm{a}$ & $54 \mathrm{~b}$ \\
\hline $\mathrm{CV}(\%)$ & $1,1 \mathrm{a}$ & 19,1 & 9,2 \\
\hline
\end{tabular}

*Médias seguidas por letras distintas diferem entre si, pelo teste de Tukey, a 5\% de probabilidade de erro. 

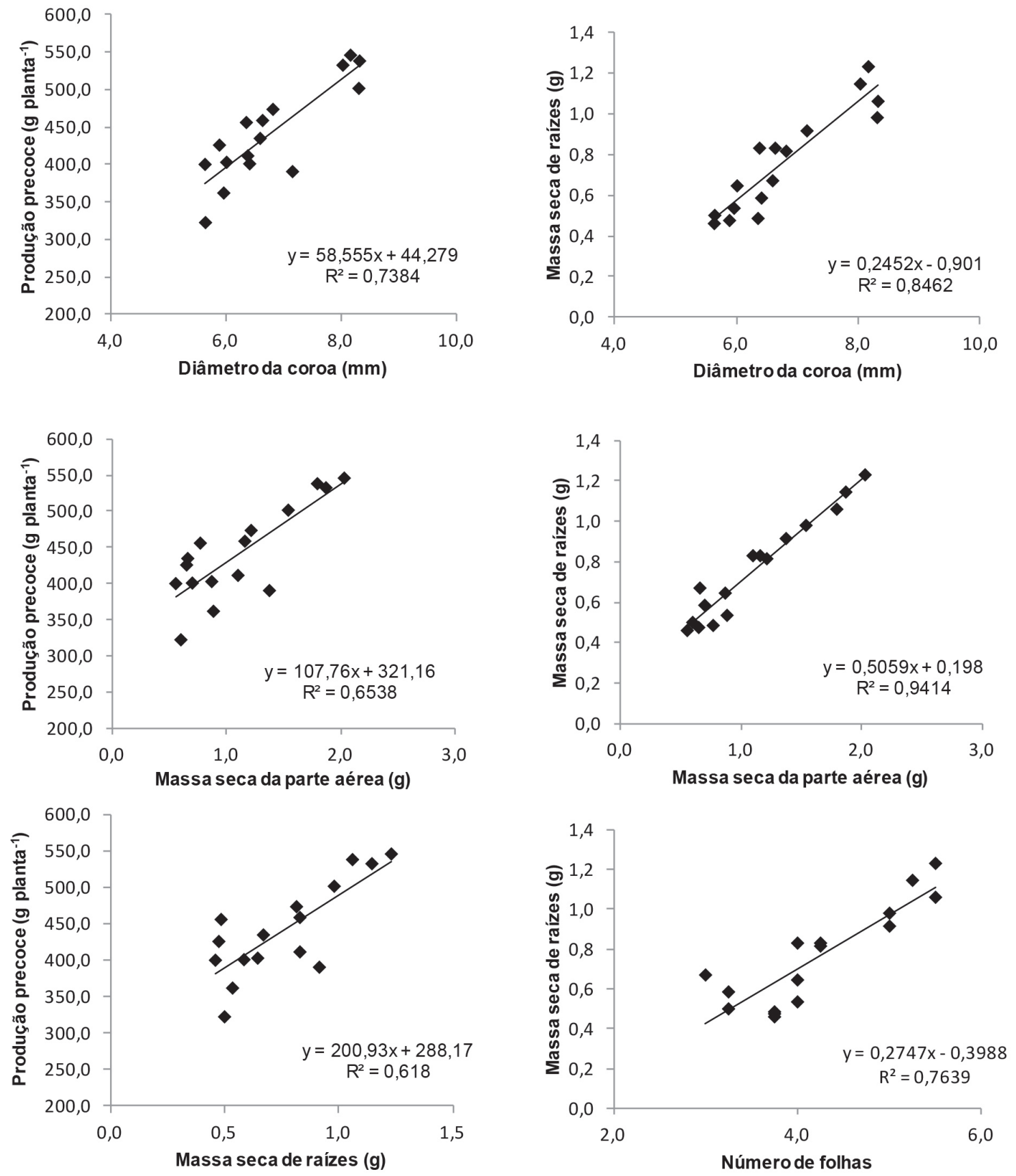

FIGURA 1 - Correlação de Pearson entre os parâmetros de qualidade da muda e a produção de frutas no período precoce: Diâmetro da coroa (A), massa seca da parte aérea (B) e massa seca de raízes (C) e correlação entre parâmetros vegetativos com a massa seca de raízes: Diâmetro da coroa (D), massa seca de parte aérea (E) e número de folhas (F). Significativo a $5 \%$ de probabilidade de erro. Pelotas, 2015. 
TABELA 3 - Número de frutas (NF), massa fresca (MF) e tamanho médio de frutas (TM) obtidos durante o período de produção precoce e total do morangueiro proveniente de mudas produzidas em diferentes volumes de alvéolo da bandeja. Pelotas, 2015.

\begin{tabular}{|c|c|c|c|c|c|c|}
\hline \multirow{3}{*}{ Cultivares } & \multicolumn{3}{|c|}{ Produção precoce } & \multicolumn{3}{|c|}{ Produção total } \\
\hline & NF & MF fresca & TM & NF & MF & TM \\
\hline & & $\left(\right.$ g planta $\left.^{-1}\right)$ & $\left(\mathrm{g}\right.$ fruta $\left.^{-1}\right)$ & & $\left(\right.$ g planta $\left.^{-1}\right)$ & $\left(\mathrm{g}\right.$ fruta $\left.^{-1}\right)$ \\
\hline Aromas & $21,0 b^{*}$ & $419,6 \mathrm{a}$ & $20,0 \mathrm{~ns}$ & $59,3 \mathrm{~ns}$ & $920,0 \mathrm{~ns}$ & $15,5 \mathrm{~ns}$ \\
\hline Camarosa & $23,8 \mathrm{a}$ & $462,2 \mathrm{a}$ & 19,4 & 58,2 & 905,9 & 15,7 \\
\hline \multirow[t]{2}{*}{ Média } & 22,4 & 440,9 & 19,7 & 58,7 & 912,9 & 15,6 \\
\hline & \multicolumn{6}{|c|}{ Volume de substrato $(\mathrm{mL})$} \\
\hline 50 & $19,4 b$ & $395,2 b$ & $20,4 \mathrm{~ns}$ & $58,4^{\mathrm{ns}}$ & $911,0 \mathrm{ab}$ & $15,7 \mathrm{~ns}$ \\
\hline 100 & $21,0 b$ & $405.6 b$ & 19,2 & 54,6 & $822,4 b$ & 15,1 \\
\hline 180 & $22,0 b$ & $433,4 b$ & 19,7 & 56,9 & $883,8 \mathrm{ab}$ & 15,5 \\
\hline 312 & $27,0 \mathrm{a}$ & $529,3 \mathrm{a}$ & 19,6 & 65,2 & $1034,5 \mathrm{a}$ & 15,9 \\
\hline Média & 22,4 & 440,9 & 19,7 & 58,7 & 912,9 & 15,6 \\
\hline $\mathrm{CV}(\%)$ & 12,6 & 14,1 & 6,4 & 14,8 & 15,5 & 5,4 \\
\hline
\end{tabular}

*Médias seguidas por letras distintas diferem entre si, pelo teste de Tukey, a 5\% de probabilidade de erro.

\section{CONCLUSÕES}

Maior precocidade e produção de frutas são obtidas com mudas produzidas em recipientes de volume de alvéolos de $312 \mathrm{~mL}$, em decorrência do maior diâmetro da coroa, massa seca de parte aérea e raízes.

Existe uma correlação positiva entre os parâmetros de qualidade da muda e a produção de frutas no período precoce.

\section{AGRADECIMENTOS}

Os autores agradecem à CAPES, pela bolsa de doutorado sanduíche concedida à primeira autora, processo BEX 9734-11-2, ao CNPq e à CAPES pelo auxílio financeiro e bolsas.

\section{REFERÊNCIAS}

ANTUNES, L. E. C.; PERES, N. A. Strawberry Production in Brazil and South America. International Journal of Fruit Science, Philadelphia, v. 13, n. $1-2,2013$.
BARTCZAK, M.; LISIECKA, J.; KNAFLEWSKI. M. Correlation between selected parameters of planting material and strawberry yield. Folia Horticulturae, Cracóvia, v. 22, n. 1, p. 9-12, 2010.

BISH, E. B., CANTLIFFE, D. J.; CHANDLER, C. $\mathrm{K}$. Temperature conditioning and container size affect early season fruit yield of strawberry plug plants in a winter, annual hill production system. HortScience, Alexandria, v. 37, p. 762-764, 2002.

CALVETE, E. O.; ROCHA, H. C.; TESSARO, F.; CECCHETTI, D.; NIENOW, A. A.; LOSS, J. T. Polinização de morangueiro por Apis mellifera em ambiente protegido. Revista Brasileira de Fruticultura, Jaboticabal, v. 32, n. 1, p. 181-188, 2010.

CEAGESP. Normas de classificação de morango. São Paulo: CQH/CEAGESP, 2002. 6 p. (Documento, 22).

COCCO, C.; ANDRIOLO, J. L., ERPEN, L.; CARDOSO, F. L.; CASAGRANDE, G. S. Development and fruit yield of strawberry plants as affected by crown diameter and plantlet growing period. Pesquisa Agropecuária Brasileira, Brasília, v. 45, n. 7 , p. 730-736, 2010. 
DAVALOS-GONZALEZ,P.A.;NARRO-SANCHEZ, J.; JOFRE-GARFIAS, A.E.; HERNANDEZ RAZO, A. R.; VAZQUEZ-SANCHEZ, M. N. Influence of the genotype, type of plant and population density on strawberry productivity and fruit quality under macrotunnel. Acta Horticulturae, Leuven, v. 842, p. 91-94, 2009.

DURNER, E. F.; POLING, E. B.; MAAS, J. L. Recent advances in strawberry plug transplant technology. HortTechnology, Alexandria, v. 12, p. 545-550, 2002.

FERREIRA, D. F. Sisvar: a computer statistical analysis system. Ciência e Agrotecnologia, Lavras, v. 35, n. 6, p. 1039-1042, 2011.

FURLANI, P. R.; FERNANDEZ JÚNIOR, F. Cultivo hidropônico de morango em ambiente protegido. In: SIMPÓSIO NACIONAL DO MORANGO \& ENCONTRO DE PEQUENAS FRUTAS E FRUTAS NATIVAS DO MERCOSUL, 2., 2004, Pelotas. Anais... Pelotas: EMBRAPA, 2004. p.102-115. (Documentos, 124).

GIMÉNEZ, G.; ANDRIOLO, J. L.; JANISCH, D.; COCCO, C.; PICIO, M. D. Cell size in trays for the production of strawberry plug transplants. Pesquisa Agropecuária Brasileira, Brasília, v. 44, n. 7, p. 726-729, 2009.

HUANG, P. W.; SANTOS, B. M.; WHITAKER, V. M. Effects of cell size on the production of containerized strawberry transplants in Florida. Proceedings Florida State Horticultural Society, Lake Alfred, v. 124, p. 184-187, 2011.

KUROKURA, T.; MIMIDA, N.; BATTEY, N. H.; HYTÖNEN, T. The regulation of seasonal flowering in the Rosaceae. Journal of Experimental Botany, Lancaster, v. 64, n. 14, p. 4131-4141, 2013.

MENZEL, C. M.; SMITH, L. Effect of Time of Planting and Plant Size on the Productivity of 'Festival' and 'Florida Fortuna' Strawberry Plants in a Subtropical Environment. HortTechnology, Alexandria, n. 22, v. 3, p. 330-337, 2012.
OLIVEIRA, R. P. de; SCIVITTARO, W. B. Desempenho produtivo de mudas nacionais e importadas de morangueiro. Revista Brasileira de Fruticultura, Jaboticabal, v. 28, n. 3, p. 520-522, 2006.

PASSOS, F. A; TRANI, P. E; CARVALHO, C. R. L. Desempenho agronômico de genótipos de morangueiro. Horticultura Brasileira, Vitoria da Conquista, v. 33, n. 2, p. 267-271, 2015.

RAHMAN, M. M.; RAHMAN, M. M.; HOSSAIN, M. M.; KHALIQ, Q. A.; MONIRUZZAMAN M. Effect of planting time and genotypes growth, yield and quality of strawberry (Fragaria $x$ ananassa Duch.). Scientia Horticulturae, Amsterdam, v. 167, p. 56-62, 2014.

SANTOS, A. M.; MEDEIROS, A. R. M. Morango: produção frutas do Brasil. 40. ed. Pelotas: Embrapa Clima Temperado, 2003. 81 p.

SANTOS, B. M., STANLEY, C. D.; WHIDDEN, A. J.; SALAME-DONOSO, T. P., WHITAKER, V. M.; HERNANDEZ-OCHOA, I. M.; HUANG, P. W.; TORRES-QUEZADA, E. A. Improved sustainability through novel water management strategies for strawberry transplant establishment in Florida, United States. Agronomy, Basel, v. 2, n. 4, p. 312-320, 2012.

SBCS - Sociedade Brasileira de Ciência Do Solo. Manual de adubação e calagem para os Estados do Rio Grande do Sul e Santa Catarina. Porto Alegre: SBCS/CQFS, 2004. 400p.

TORRES-QUEZADA, E. A.; ZOTARELLI, L.; WHITAKER, V.M.; SANTOS, B.M.; HERNANDEZOCHOA, I. Initial crown ciameter of strawberry bare-root transplants affects early and total fruit yield. HortTechnology, Alexandria, v. 25 n. 2, p. 203-208, 2015. 